\title{
Effect of intrauterine copper device on cervical cytology and its comparison with other contraceptive methods
}

\author{
Sipra Bagchi ${ }^{1}$, Shanti Sah ${ }^{1}$, Tanu Agrawal ${ }^{2}$ \\ ${ }^{1}$ Department of Obstetrics and Gynaecology, SRMS Institute of Medical Sciences, Bareilly, Uttar Pradesh, India \\ ${ }^{2}$ Department of Pathology, SRMS Institute of Medical Sciences, Bareilly, Uttar Pradesh, India
}

Received: 22 June 2016

Accepted: 12 July 2016

*Correspondence:

Dr. Sipra Bagchi,

E-mail: drsiprabagchi@gmail.com

Copyright: ( ) the author(s), publisher and licensee Medip Academy. This is an open-access article distributed under the terms of the Creative Commons Attribution Non-Commercial License, which permits unrestricted non-commercial use, distribution, and reproduction in any medium, provided the original work is properly cited.

\section{ABSTRACT}

Background: The intrauterine device (IUD) is the most commonly used reversible family planning method all over the world .The risk of cervical neoplasia associated with use of an intrauterine device (IUD), specially the copper releasing one, has been an important concern. The aim and objectives of the study was to determine safety of copper IUCD with regard to changes in cervical cytology and to compare the changes with other methods of temporary contraception.

Methods: This was a prospective study carried out at a tertiary care institute for a period of 3 years. A total of 200 women of age group 18-40 years were included. 100 subjects who opted $\mathrm{Cu}-\mathrm{T}$ 380A IUD were compared with 100 controls that had either opted other mode of temporary contraception like barrier, injectable, oral or did not use any method. Detailed history and examination of all subjects were done. All the women were subjected to conventional Pap smear and were followed at 6 months of interval for 1 year and then yearly up to 3 years. In each visit thorough pelvic examination was done and PAP smears were taken.

Results: Among women using IUCD, 67.7\% showed normal cytology as compared to $72.0 \%$ of the controls. On follow up, the incidence of normal cytology decreased (40\%) with increased duration of use (up to 3 years). Incidence of inflammatory smear though first decreased up to 1 year (21.8\%) but then gradually increased up to 2 years (37.0\%) of use and then again decreased to $20.0 \%$ up to 3 years of use. ASCUS was found in only one case that used the device up to 2 years of use. LSIL was detected in 2 cases (20\%) using IUD up to 3 years. No case of high grade intraepithelial lesion (HSIL) or invasive cancer was seen.

Conclusions: There was no significant risk of cervical dysplasia or invasive carcinoma in IUCD users up to 2 years of use while other contraceptives (except barrier one) showed increased incidence of mild dysplasia (LSIL) after 1 year of use. Though risk of cervical malignancy is less with intrauterine copper devices, regular follow up should be done in long term users.

Keywords: PAP smear, Cervical dysplasia, Contraception

\section{INTRODUCTION}

The intrauterine device (IUD) is the most frequently used reversible family planning method in the world .The intrauterine device (IUD), primarily in the form of the copper IUD, is used by more than 150 million women around the world. The Copper T-380A has a very low failure rate of less than 1 per 100 women in the first year of use. So in terms of efficacy, it is one of the best contraceptives. ${ }^{1}$ Overall, the number of adverse events is low, making the Copper T-380A a very safe contraceptive method. The most common reasons for the discontinuation of this method are menstrual bleeding and dysmenorrhea. ${ }^{1}$ Intrauterine devices (IUDs) prevent pregnancy by creation of a sterile inflammatory response in the endometrium. Additionally, hormone-releasing IUDs or intrauterine systems (IUSs) release progestins or progesterone into the uterus. Both of these mechanisms 
may affect users' risk for neoplasia. ${ }^{2}$ This study was carried out to determine its safety with regard to changes in cervical cytology and to compare with other methods of temporary contraception.

\section{METHODS}

In this prospective study a total of 200 women of age group 18-40 years were included. 100 subjects who opted $\mathrm{Cu}$-T 380A IUD were compared with 100 controls that had either opted other mode of temporary contraception like barrier, injectable, oral or did not use any method. Distribution of subjects in control group is shown in table 1 .

All the subjects were matched for age, parity and socioeconomic status. Majority of cases both in study and control group were between 20-30 years of age. Detailed history and examination of all subjects were done. All the women were subjected to conventional Pap smear. The smears were taken from the exocervix and endocervix by an Ayre's spatula and cytobrush. Standard method of fixation was used and slides were subjected to Papanicolaou's staining. Cytology of cervix was reported according to the Bethesda classification. All subjects were followed at 6 months of interval for 1 year and then yearly up to 3 years. In each visit thorough pelvic examination was done to confirm presence of IUD and to diagnose any other genital pathology. PAP smears were taken at each visit. The results were analysed using $\mathrm{Z}$ test for proportions.

\section{RESULTS}

Table 1: Distribution of subjects in control group $(n=100)$.

\begin{tabular}{|l|l|}
\hline Contraceptive methods & Number (\%) \\
\hline OCP & 15 \\
\hline DMPA & 20 \\
\hline Barrier & 25 \\
\hline No method (coitus interruptus) & 40 \\
\hline
\end{tabular}

All the cases were subjected to Pap smear, of which 4 cases in Cu-T380 A group had unsatisfactory smear and were excluded from the study. Out of the remaining 96 cases, 65 cases $(67.7 \%)$ had normal preinsertion smears and 31 cases $(32.3 \%)$ had inflammatory smears. In the control group 72 subjects $(72 \%)$ had normal smears, 20 subjects $(20 \%)$ had inflammatory smears, 2 cases had atypia of squamous cells of undetermined significance (ASCUS), 2 cases had low grade intraepithelial lesion (LSIL) and one case had reactive/reparative smear.

Among the women using IUCD, 67.7\% (65/96) showed normal cytology as compared to $72.0 \%$ (72/100) of the controls (Table 2). On follow up it was found that the incidence of normal cytology decreased with increased duration of use. It was $67.7 \%$ on recruitment but decreased to $40.0 \%$ up to 3 years of use. Incidence of infection though first decreased up to 1 year $(21.8 \%)$ but then gradually increased up to 2 years $(37.0 \%)$ of use and then again decreased to $20.0 \%$ up to 3 years of use.

ASCUS was not found on recruitment but was seen in only one case that used the device up to 2 years of use. Likewise LSIL though not seen initially was detected in 2 cases (20\%) using IUD up to 3 years. No case of high grade intraepithelial lesion (HSIL) or invasive cancer was seen (Table 2).

In the control group, the subjects could be followed only upto 2 visits i.e. upto 1 year of use or no use (in non contaceptive group) as most of them did not come back for further follow up.

Incidence of infection decreased in women not using any contraceptive method from $15 \%$ to $5.0 \%$. Though it remained almost same in cases using OCP. Women using barrier contraception did not have inflammatory smear on recruitment but showed $11 \%$ incidence at first visit after 6 months that dropped to $6.2 \%$ at second visit. In DMPA users there was slight decrease in incidence of infection from $10 \%$ to $7.69 \%$ (Table $3 a$ and $3 b$ ).

Incidence of ASCUS increased from $2.5 \%$ on recruitment to $15.8 \%$ at second visit in women not using any contraceptive method. Similarly in OCP group ASCUS increased from $6.7 \%$ to $21.4 \%$ at first visit. No case of ASCUS was found in women using barrier contraception but in DMPA group its incidence was $0 \%$ on recruitment that increased to $15.4 \%$ at first visit and then $20 \%$ at second visit (Table $3 \mathrm{a}$ and $3 \mathrm{~b}$ ).

Though no case of LSIL was seen on recruitment but could be seen at second followup visit in $10.5 \%, 11 \%$ and $6.7 \%$ subjects of no contraceptive, OCP and DMPA groups respectively. It was found in $8 \%$ cases using barrier contraception on recruitment but was not seen on follow up.

\section{DISCUSSION}

In the present study the maximum no. of normal smear $(35 / 57 ; 61.4 \%)$ were found when the duration of CU-T was less than one year. As the duration of $\mathrm{Cu}-\mathrm{T}$ increased, incidence of infection reached a maximum incidence of $37 \%$ with duration of use of CU-T up to 2 years but there was a fall in the incidence up to $20 \%$ after 3 years of use (Table 2). In study by Nayak et al incidence of infection increased reaching a maximum incidence of $35.4 \%$ with duration of $\mathrm{Cu}-\mathrm{T}$ up to 3 years. ${ }^{3}$ Study by Agarwal $\mathrm{K}$ et al showed slight increase in incidence of inflammatory smear in study group in comparison to control group which was statistically not significant. ${ }^{4}$ In their study mean duration of IUCD use was 2 years. Ashwani $\mathrm{R}$ et al reported an incidence of inflammatory smear as $57 \%$ at 6 weeks, $72.6 \%$ at 6 months of $\mathrm{Cu}-\mathrm{T}$ insertion. ${ }^{5}$ Alka Patankar et al also found 
statistically not significant slightly increased incidence of inflammatory smear in IUCD group compared to control group $(75.2 \% \mathrm{Vs} 68.4 \%){ }^{6}$ As in present study, they also found predominantly increased incidence of inflammatory cytological smear in initial 2 years.
In our study ASCUS was found in only one case that used the device up to 2 years of use. SR Nayak et.al reported ASCUS in four subjects $(1.4 \%)$ above the age of 30 years and having duration of insertion of IUD of 2-3 years. ${ }^{3}$

Table 2: Cervical cytology based on duration of use of Cu-T380 A.

\begin{tabular}{|c|c|c|c|c|c|c|c|c|c|c|}
\hline \multirow{3}{*}{$\begin{array}{l}\text { Cervical cytology } \\
\text { findings }\end{array}$} & & & \multicolumn{8}{|c|}{ Duration of CU-T 380A use } \\
\hline & \multicolumn{2}{|c|}{$\begin{array}{l}\text { Preinsertion } \\
n=96\end{array}$} & \multicolumn{2}{|c|}{$\begin{array}{l}\text { First visit } \\
(6 \text { months }) \\
n=57\end{array}$} & \multicolumn{2}{|c|}{$\begin{array}{l}\text { Second visit } \\
(1 \text { year) } \\
n=32\end{array}$} & \multicolumn{2}{|c|}{$\begin{array}{l}\text { Third visit } \\
\text { ( } 2 \text { years) } \\
n=27\end{array}$} & \multicolumn{2}{|c|}{$\begin{array}{l}\text { Fourth visit } \\
\text { ( } 3 \text { years) } \\
n=10\end{array}$} \\
\hline & Cases & $\%$ & Cases & $\%$ & Cases & $\%$ & Cases & $\%$ & Cases & $\%$ \\
\hline Normal & 65 & 67.7 & 35 & 61.4 & 17 & 53.1 & 09 & 33.3 & 04 & 40.0 \\
\hline Inflammatory & 31 & 32.3 & 08 & 14.0 & 07 & 21.8 & 10 & 37.0 & 02 & 20.0 \\
\hline Reactive/reparative & - & - & 14 & 24.5 & 08 & 25.0 & 07 & 25.9 & 02 & 20.0 \\
\hline ASCUS & - & - & - & - & - & - & 01 & 3.7 & - & - \\
\hline LSIL & - & - & - & - & - & - & - & - & 02 & 20.0 \\
\hline
\end{tabular}

Table 3A: Cervical cytology in control group.

\begin{tabular}{|c|c|c|c|c|c|c|}
\hline \multirow{2}{*}{ Cytology } & \multicolumn{3}{|c|}{ No contraceptive $n=40$} & \multicolumn{3}{|l|}{ OCP $n=15$} \\
\hline & On recruitment & $1^{\text {st }}$ visit $^{*}$ & $2^{\text {nd }}$ visit $^{\#}$ & On recruitment & $1^{\text {st }}$ visit* & $2^{\text {nd }}$ visit $^{\#}$ \\
\hline Normal & $21(52.5 \%)$ & $12(48 \%)$ & $9(47.4 \%)$ & $11(73.3 \%)$ & $05(35.7 \%)$ & $06(66.7 \%)$ \\
\hline Inflammatory & $15(37.5 \%)$ & $10(40 \%)$ & $05(26.3 \%)$ & $03(20 \%)$ & $04(28.6 \%)$ & $02(22.2 \%)$ \\
\hline Reac./reparative & $03(7.5 \%)$ & $02(8 \%)$ & - & - & $02(14.3 \%)$ & - \\
\hline ASCUS & $01(2.5 \%)$ & $01(4 \%)$ & $03(15.8 \%)$ & $01(6.7 \%)$ & $03(21.4 \%)$ & - \\
\hline LSIL & - & - & $02(10.5 \%)$ & - & - & $01(11.1 \%)$ \\
\hline Total & 40 & 25 & 19 & 15 & 14 & 09 \\
\hline
\end{tabular}

* After 6 months; \# After 1 year

Table 3B: Cervical cytology in control group.

\begin{tabular}{|c|c|c|c|c|c|c|}
\hline \multirow{2}{*}{ Cytology } & \multicolumn{3}{|l|}{ Barrier $\mathbf{n}=\mathbf{2 0}$} & \multicolumn{3}{|l|}{ DMPA $n=25$} \\
\hline & On recruitment & $1^{\text {st }}$ visit $^{*}$ & $2^{\text {nd }}$ visit $^{\#}$ & On recruitment & $1^{\text {st }}$ visit* & $2^{\text {nd }}$ visit $^{\#}$ \\
\hline Normal & $22(88 \%)$ & $16(88.8 \%)$ & $11(68.7 \%)$ & $18(90 \%)$ & $10(76.9 \%)$ & $10(66.6 \%)$ \\
\hline Inflammatory & - & $02(11 \%)$ & $01(6.2 \%)$ & $02(10 \%)$ & $01(7.69 \%)$ & - \\
\hline Reac./reparative & $01(04 \%)$ & - & $04(25 \%)$ & - & - & $01(6.66 \%)$ \\
\hline ASCUS & - & - & - & - & $02(15.4 \%)$ & $03(20 \%)$ \\
\hline LSIL & $02(08 \%)$ & - & - & - & - & $01(6.66 \%)$ \\
\hline Total & 25 & 18 & 16 & 20 & 13 & 15 \\
\hline
\end{tabular}

* After 6 months; \# After 1 year

LSIL was found in 2 cases using IUD up to 3 years in present study but no case of HSIL was seen. Alka Patankar et al did not find any case of dysplasia including ASCUS, LSIL or HSIL. ${ }^{6}$ LSIL in study by SR Nayak et al was found in four subjects $(1.4 \%)$ and all were above the age of 30 years. In two of these $\mathrm{Cu}-\mathrm{T}$ was in situ for more than 3 years and in two others it was for 2 years. They concluded that incidence of ASCUS and LSIL increases with the increase in duration of insertion being maximum when the duration of insertion is more than 3 years. $^{3}$ A large cytological study was conducted on 2603 women using copper containing intrauterine devices by Luthra UK et al. ${ }^{7}$ They followed women up to a maximum period of 60 months. $2.5 \%$ of initial smears showed dysplastic lesions. They grouped the 60 months into 5 time intervals of 1 year each. The annual rates of dysplasia at follow up were $4.2 \%, 1.6 \%, 3.8 \%, 0.9 \%$ and $3.0 \%$. The rate of dysplasia in women with initially 
negative or inflammatory smears did not change significantly during five years. ${ }^{7}$ Agrawal K et al reported LSIL and HSIL in $1 \%$ and $2 \%$ of IUCD users compared to none in controls. The women with HSIL were ones using the IUCD for 15 and 25 years following forgotten insertion. ${ }^{4}$

Among the control group of our study incidence of inflammatory smear decreased with increased duration of use in barrier and DMPA group while in OCP group and in women not using any contraceptive the incidence first increased after 6 months and then decreased after 1 year of follow up. ASCUS incidence increased in OCP and DMPA group with increase in duration of use. Similarly women not using any contraceptive method also showed increase in ASCUS incidence on follow up from $2.5 \%$ to $15.8 \%$. No case of LSIL or HSIL seen on recruitment except in barrier group (8\%) in which it was not seen later on while in other groups LSIL was found at 1 year of follow up.

Bariş II and Arman Karakaya Y investigated, the effects of the main contraceptive methods used and changes on epithelial abnormalities and vaginal flora changes in cervical cytology in 526 patients. In the study group, $65.2 \%(n=343)$ were using an IUD, 20.3\% ( $n=107)$ a hormonal contraception method and $14.4 \% \quad(n=76)$ a barrier method. No significant relationship was found between contraception methods and squamous and glandular epithelial abnormalities $(\mathrm{p}=0.65) .{ }^{8}$ Melamed et al found a significantly increased carcinoma in situ and dysplasia incidence in women using OC compared to those using a diaphragm or IUD. ${ }^{9}$ Moreno et al reported no increase in risk of cervical neoplasia development in patients using OC for less than 5 years. However, the use of OC for more than 5 years was found to increase risk in HPV (+) women. ${ }^{10}$

So when compared in the present study, there was no significant risk of cervical dysplasia or invasive carcinoma in IUCD users up to 2 years of use while other contraceptives (except barrier one) showed increased incidence of mild dysplasia (LSIL) after 1 year of use. It can be concluded from this study that, though risk of cervical malignancy is less with intrauterine copper devices, regular follow up should be done in long term users.

\section{ACKNOWLEDGEMENTS}

Authors appreciate and thank the department of pathology and the lab staff for their help and immense support. We are also grateful to all those authors whose articles are cited and included in references of this manuscript.

Funding: No funding sources

Conflict of interest: None declared

Ethical approval: The study was approved by the Institutional Ethics Committee

\section{REFERENCES}

1. Kaneshiro B, Aeby T. Long-term safety, efficacy, and patient acceptability of the intrauterine Copper T-380A contraceptive device. Int J Womens Health. 2010;2:211-20.

2. Curtis KM, Marchbanks PA, Peterson HB. Neoplasia with use of intrauterine devices. Contraception. 2007;75(6 Suppl):S60-9.

3. Nayak SR, Latha Chaitanya L. Clinicocytological study in copper-T users. J Obstet Gynecol India. 2007;57(3):231-3

4. Agarwal K, Sharma U, Acharya V. Microbial and cytopathological study of intrauterine contraceptive device users. Indian J Med Sci. 2004;58:394-9.

5. Ashwani R, Rao B, Shobha VS, Shroff RR, Purandare M. Cytology in CuT users. J Obstet Gynae Ind. 1988;38:717-21.

6. Patankar A, Wakankar R. Microbial and Clinicocytological Study in Copper-T (CU-T) Users. Journal of Evolution of Medical and Dental Sciences 2015;4(47):8143-52.

7. Luthra UK, Mitra AB, Prabhakar AK, Agarwal SS, Bhatnagar P. Cytologic monitoring of women using copper containing intrauterine devices- Five year follow up study; Acta Cytologica. 1982;26:619-22.

8. Bariş II, Arman Karakaya Y. Effects of contraception on cervical cytology: data from Mardin City. Turkish J path. 2013;29(2):117-21.

9. Melamed MR, Flehinger BJ. Early incidence rates of precancerous cervical lesions in women using contraceptive. Gynecol Oncol. 1973;1:290-8.

10. Moreno V, Bosch FX, Muñoz N, Meijer CJ, Shah $\mathrm{KV}$, Walboomers JM, et al. Effect of oral contraception on risk of cervical cancer in women with human papillomavirus infection. International Agency for Research of Cancer multicentric case control study. Lancet. 2002;359:1085-92.

Cite this article as: Bagchi S, Sah S, Agrawal T. Effect of intrauterine copper device on cervical cytology and its comparison with other contraceptive methods. Int J Reprod Contracept Obstet Gynecol 2016;5:2795-8. 